\title{
Association between perceived stress, self-rated health, work productivity and stress management interventions - a study of employees in the Slovenian processing industry
}

\author{
Nataša Sedlar Kobe', Alenka Dovč², Andrea Backović Juričan', \\ Jerneja Farkaš Lainščak ${ }^{3}$
}

${ }^{\prime}$ National Institute of Public Health, Trubarjeva cesta 2, 1000 Ljubljana, Slovenia

${ }^{2}$ Chamber of Commerce and Industry of Slovenia, Dimičeva ulica I3, I504 Ljubljana, Slovenia

${ }^{3}$ Department of Research, General Hospital Murska Sobota/ National Institute of Public Health, Ulica dr. Vrbnjaka 6, 9000 Murska Sobota/ Trubarjeva cesta 2, 1000 Ljubljana, Slovenia natasa.sedlar@nijz.si; alenka.dovc@gzs.si; andrea.backovic-jurican@nijz.si; jerneja.farkas@sb-ms.si

\begin{abstract}
Introduction: Employees' high levels of perceived workplace stress has been associated with impaired health and lost productivity due to sickness absenteeism and sickness presenteeism. As a result, there's been a growing interest in programs and interventions to reduce stress at work among organizations. Methods: The study was conducted as a part of the project Healthy on a square II - workplace health promotion for employees in the chemical and other processing industries, in March 2016 in the sample of $\mathrm{N}=796$ employees in processing industries. The aim of the study was to examine the relationship between employees' frequency of perceived stress, self-rated health, sickness presenteeism, sickness absenteeism and implemented stress management interventions. Results: The results indicated that higher frequency of perceived stress is associated with poorer self-rated health, higher number of health problems in the past month and more days of sickness absenteeism and sickness presenteeism in the past year. Regarding the implemented activities for managing work-related stress in included organisations, most commonly reported activities were informing employees about work-related stress and its consequences and stress management training provision, while organisational-level interventions were rare. Discussion: The study highlights the need for systematic implementation of stress management interventions and research on their effect on employees' well-being and work productivity.

Key words: stress at work, self-rated health, sickness absenteeism, sickness presenteeism, stress management interventions
\end{abstract}


tress has been given several definitions, but generally refers to individual's physical, mental and emotional response to environmental demands or pressures that are perceived as straining or exceeding individual's perceived adaptive capacities (Cohen et al., 1986). So far, a growing body of evidence suggests that excess or long-term stress contributes to impaired physical and psychological health (i.e. Schneiderman et al., 2005). Similarly, impaired employee's physical and psychological health has been shown to be one of the most undesirable consequences of high-levels of stress at work (i.e. Cox, Griffiths and Rial-Gonzales, 2000; Novak, Sedlar and Šprah, 2014; Stansfeld and Candy, 2006).

Stress at work gained increased attention among professionals and researchers over the last decades, mostly due to its high economic and human costs for organisations. Numerous studies (i.e. Biron et al., 2006; MacGregor, Cunningam and Caverley, 2008) have confirmed that impaired employee's health and high levels of stress at the workplace result in lost productivity, arising from two sources: absenteeism and presenteeism. The first one refers to an employee's time away from work due to illness or disability (i.e. Johns, 2003), while the second one occurs when employee comes to work ill and his job performance is limited in some aspects by a health problem (i.e. Johns 2010). Both outcomes are considered part of a continuum, with presenteeism being placed between full work engagement and absenteeism (Johns, 2009) and employees are likely to transit from one to another over time (i.e. Escorpizo et al., 2007).

To measure work-related stress across various types of jobs and organizations several self-report instruments have been developed. However, sometimes when monitoring stress at work comprehensive scales might not be accepted by the target organisations. Therefore researchers (i.e. Elo et al., 2003) proposed the use of a single-item measure of stress. The scale refers to the general experience of stress, not explicitly to work-related stress, but was shown to be a valid instrument for group-level analysis when monitoring stress at work. In a similar vein, a single-item measure of self-rated health is generally accepted as an easy to implement and valid indicator to measure individual's health status (i.e. Borg, Kristensen and Burr, 200o).

Employee's stress and its negative outcomes have become a concern for many organisations. Therefore there is a growing interest in programs and interventions to reduce stress at work (González, Cockburn and Irastorza, 2010; Irastorza et al., 2016). Implemented stress management interventions in occupational settings most often focus on reducing the presence of work relatedstress or aim to minimize the negative outcomes of exposure to these stressors. However, the research shows that their effect most importantly depends on the intervention type (Richardson and Rothstein, 2008).

Using a sample of Slovenian industrial workers, our study investigated the relationship between employees' level of perceived stress in terms of frequency, self-rated health, sickness presenteeism, sickness absenteeism and implemented stress management interventions in included organisations. 


\section{Methods}

Data for his cross-sectional study were collected in March 2016 as part of the project 'Zdravi na kvadrat II' (engl.: 'Healthy on a square II') - workplace health promotion for employees in the chemical and other processing industries, conducted in 17 Slovenian companies in processing industry ( $n=2$ smallsized companies (<50 employees); $n=11$ middle-sized (50-250 employees); $n=4$ large-sized (>250 employees)). $2-74 \%$ of the population size of included organisations completed the self-administered questionnaire.

The average age of the final sample $(N=796)$ was 41 years and there was a slight male predominance (55.2\%). Third of the participants reported having completed secondary educational level, while approximately $26 \%$ completed vocational and higher vocational educational level/graduate degree. Almost half of the participants reported having sufficient income to meet their (household's) needs (46.6\%), while the rest of the sample reported having (occasional) difficulties. Most of the participants were performing sedentary (43.6\%), mostly standing $(34.4 \%)$ or light physical work (36.5\%). Further details are presented in Table 1.

Table 1: Socio-demographic characteristics of the sample.

\begin{tabular}{|c|c|}
\hline & Total sample $(N=796)$ \\
\hline Gender (male), $n(\%)$ & $439(55.2)$ \\
\hline Age (years), $M \pm S D$ & $40.9 \pm 10.3$ \\
\hline \multicolumn{2}{|l|}{ Educational level, $n(\%)$} \\
\hline Primary or less & $92(11.4)$ \\
\hline Vocational & $205(25.8)$ \\
\hline Secondary & $267(33.5)$ \\
\hline Higher vocational, graduate degree & $204(25.6)$ \\
\hline Postgraduate degree (master's, doctorate) & $28(3.5)$ \\
\hline \multicolumn{2}{|l|}{ Subjective sufficiency of income, $n(\%)$} \\
\hline Sufficient income to meet (household's) needs & $371(46.6)$ \\
\hline Occasional difficulties & $338(42.5)$ \\
\hline Difficulties & $87(10.9)$ \\
\hline \multicolumn{2}{|l|}{ Type of work, $f(\%)$} \\
\hline Sedentary work & $375(43.6)$ \\
\hline Mostly standing & $296(34.4)$ \\
\hline Light physical work/standing or walking without major physical strain & $314(36.5)$ \\
\hline Heavy physical work/often lifting or moving heavy things & $167(19.4)$ \\
\hline Forced posture & $132(15.3)$ \\
\hline Repetitive movements & $200(23.3)$ \\
\hline
\end{tabular}

Questions regarding socio-demographical data (gender, age, educational level, subjective sufficiency of income, type of work) comprised the initial section of the questionnaire.

Frequency of perceived stress was measured through a question: 'How often do you feel tense, stressed or under intense pressure?' (1 - never; 2 - rarely; 
3 - sometimes; 4 -often; 5 - every day). Response categories 4 and 5 were used to define groups with high, 3 with medium, and 1 or 2 with low perceived stress levels. Subjective assessment of individual's health was measured through a question: 'How would you assess your present health? (1 - very good; 2 - good; 3 - fair; 4 - poor; 5 - very poor). Additionally, respondents were asked to indicate whether they had experienced any of the stated health problems in the previous month (chest pain during physical activity, low back pain, neck/shoulder pain, joint pain, chronic cough and mucus, swollen legs, allergy, constipation, headache, insomnia, depressive symptoms, toothache, urination problems). The total number of reported health problems per participant was calculated. All three questions were adapted from CINDI Health Monitor Core Questionnaire (Prättälä et al., 2001).

Sickness absenteeism was measured through the question: 'How many days in the last 12 months have you been absent from work because of sick leave? (ie. Gustafsson and Marklund, 2011). To measure sickness presenteeism the question: 'Did you go to work even though you should have taken sick leave during the past 12 months? (yes; no; I have not been sick). If yes, how many times?' was used (Aronsson et al., 2000).

Furthermore, management of each included organisation was asked about implemented stress management interventions (i.e. provision of training; a redesign of the work area; for total list see Table 3), adapted from European Survey of Enterprises on New and Emerging Risks, ESENER (Cox et al., 2010).

Health and safety representative from each organisation was asked to assist with distribution and collection of questionnaires for management and employees. Employee participation was voluntary and anonymity guaranteed; the questionnaires were collected immediately after completion and sent to the project coordinator.

In total, there were $0.2-14.8 \%$ missing values per variable. Missing data were imputed using the EM algorithm, which has been demonstrated to be an effective method of dealing with missing data (Graham, 2009), and all analyses were conducted using a total of 796 participants. Kendall's tau b rank correlation coefficient was calculated to evaluate the associations between frequency of perceived stress and other variables (health-related characteristics, the number of implemented stress management interventions). Multiple linear regression was conducted to examine which of the included variables predict frequency of perceived stress. All analyses were performed using SPSS V.21 (SPSS, Chicago, Illinois, USA).

\section{Results}

Almost half of the participants (46.0\%) reported medium, 28.5\% low and $25.5 \%$ high perceived stress level. Regarding self-rated health, more than half (62.3\%) of the sample reported good or very good, $31.4 \%$ fair and $6.3 \%$ poor or very poor 
self-rated health. However, participants on average reported they have experienced three health problems in the last month. Half of the participants reported no sickness absenteeism in the past year, $24.0 \%$ one to seven days and $21.4 \%$ eight to 30 days. Similarly, almost half of the sample (46.0\%) reported no sickness presenteeism in the past year, while $33.2 \%$ one to seven days and $21.4 \%$ eight to 30 days (for details see Table 2).

\section{Table 2: Frequency of perceived stress and health-related characteristics/} outcomes of the sample.

\begin{tabular}{|c|c|}
\hline & Total sample $(N=796)$ \\
\hline Perceived stress level, $M \pm S D$ & $3.0 \pm 0.9$ \\
\hline High, $f(\%)$ & $203(25.5)$ \\
\hline Medium, $f(\%)$ & $366(46.0)$ \\
\hline Low, $f(\%)$ & $227(28.5)$ \\
\hline Self-rated health, $M \pm S D$ & $2.3 \pm 0.8$ \\
\hline Good or very good, $f(\%)$ & $496(62.3)$ \\
\hline Fair, $f(\%)$ & $250(31.4)$ \\
\hline Poor or very poor, $f(\%)$ & $50(6.3)$ \\
\hline Number of experienced health problems in the past month, $M \pm S D$ & $3.0 \pm 2.3$ \\
\hline $0-2, f(\%)$ & $362(45.5)$ \\
\hline $3-6, f(\%)$ & $371(46.6)$ \\
\hline $7-10, f(\%)$ & $63(7.9)$ \\
\hline Sickness absenteeism in the past year (days), $M \pm S D$ & $7.6 \pm 19.4$ \\
\hline o days. $f(\%)$ & $400(50.3)$ \\
\hline $1-7$ days, $f(\%)$ & $191(24.0)$ \\
\hline 8-3o days, $f(\%)$ & $170(21.4)$ \\
\hline 31-9o days, $f(\%)$ & $29(3.6)$ \\
\hline$\geq 91$ days, $f(\%)$ & $6(0.8)$ \\
\hline Sickness presenteeism in the past year (days), $M \pm S D$ & $4.6 \pm 7.5$ \\
\hline o days, $f(\%)$ & $366(46.0)$ \\
\hline $1-7$ days, $f(\%)$ & $264(33.2)$ \\
\hline 8-3o days, $f(\%)$ & $162(20.4)$ \\
\hline 31-9o days, $f(\%)$ & $3(0.4)$ \\
\hline$\geq 91$ days, $f(\%)$ & $1(0.1)$ \\
\hline
\end{tabular}

$$
{ }^{* *} p<0.01
$$

Frequency of perceived stress was significantly associated with self-rated health $\left(r=0.29^{* *}\right)$, number of experienced health problems in the past year $\left(r=0.39^{\star *}\right)$, days of sickness absenteeism $\left(r=0.12^{\star \star}\right)$ and sickness presenteeism $\left(r=0.28^{\star *}\right)$ in the past year.

Total number of implemented measures to prevent or manage work related-stress ranged from zero to five $(M \pm S D=2.2 \pm 1.5)$ in the included organisations and was significantly associated $\left(r=-0.13^{\star *}\right)$ with frequency of perceived stress. Among the most commonly implemented stress management interventions were: informing employees about work-related stress and its consequences $(58.8 \%)$, stress management training provision (35.2\%) and informing em- 
ployees about whom to adress when encountering (work-related) psychosocial problems (23.5\%). Organisational-level interventions (ie. changes to working time arrangements or to the way work is organised) were more rare (see $\mathrm{Ta}$ ble 3).

Table 3: Implemented stress management interventions in the included work organisations.

\begin{tabular}{lc}
$\begin{array}{l}\text { Informing employees about work-related stress and importance of mental } \\
\text { health and their effects on health and safety. }\end{array}$ & $\begin{array}{c}\text { (\%) of included } \\
\text { organisations }\end{array}$ \\
\hline \begin{tabular}{l} 
Provision of training on the prevention of work-related stress. \\
\hline $\begin{array}{l}\text { Informing employees about whom to address in case of (work-related) psy- } \\
\text { chosocial problems. }\end{array}$
\end{tabular} & $4(235.8)$ \\
\hline Changes to working time arrangements. & $2(11.8)$ \\
\hline Setting-up of conflict resolution procedure. & $2(11.8)$ \\
\hline $\begin{array}{l}\text { Assessment of work-related stress and psychosocial risk factors in the organ- } \\
\text { isation. }\end{array}$ & $1(5.9)$ \\
\hline Changes to the way work is organised. & $1(5.9)$ \\
\hline A redesign of the work area. & $1(5.9)$ \\
\hline Confidential counselling for employees. & $1(5.9)$
\end{tabular}

Multiple linear regression analysis was used to demonstrate whether the investigated health-related variables and outcomes significantly contribute to the frequency of perceived stress. Results are presented in Table 4. Variables included in the model explained $28 \%$ of the variability of the frequency of perceived stress. Having worse self-rated health, having experienced more health problem in the past month, being absent from work due to illness more days, being employee of an organisation that has implemented fewer stress management interventions was significantly associated with higher frequency of perceived stress even after controlling for organisation, age and gender.

Table 4: Regression model of frequency of perceived stress (adjusted $R_{2}=0.28$ ).

\begin{tabular}{lcc} 
& Beta & $p$ \\
Self-rated health & 0.198 & $<0.001$ \\
\hline Number of experienced health problems in the past month & 0.322 & $<0.001$ \\
\hline Sickness absenteeism in the past year (days) & 0.076 & 0.015 \\
\hline Sickness presenteeism in the past year (days) & 0.059 & $\mathrm{~ns}$ \\
\hline Number of implemented stress management interventions in the organisation & -0.071 & 0.025 \\
\hline Organisation & 0.028 & $\mathrm{~ns}$ \\
\hline Age & -0.044 & $\mathrm{~ns}$ \\
\hline Gender & 0.052 & $\mathrm{~ns}$ \\
\hline Education level & 0.184 & $<0.001$ \\
\hline
\end{tabular}




\section{Discussion}

The results of this study demonstrate the association between higher frequency of perceived stress and worse self-rated health, more health problems in the past month and higher level of sickness absenteeism and sickness presenteeism in the past year. The findings are in line with previous research on the healthand productivity-related consequences of high levels of perceived workplace stress (i.e. Biron et al., 2006; MacGregor et al., 2008; Stansfeld and Candy, 2006). However, days of sickness presenteeism have not significantly contributed to the higher frequency of perceived stress in the regression model. This could be partially explained by the recent meta-analysis of Miraglia and Johns (2016) where various variables pertaining to job demands (constraints on absenteeism, elevated job demands and felt stress etc.) and job and personal resources (low support, low optimism etc.) were shown to be more important in explaining presenteeism than absenteeism.

A quarter of the sample reported high frequency of perceived stress ( $\mathrm{Ta}$ ble 2). This is somewhat similar to the results of the Fifth European Working Conditions Survey, EWCS (EUROFOND, 2012) where $20 \%$ of workers reported a poor mental well-being. Also, the results regarding the frequency of sickness absenteeism and presenteeism are comparable with those obtained by the most recent EWCS study (EUROFOND, 2017); 50\% of the sample reported no sickness absenteeism (compared to 60\% reported in the EWCS), while $46 \%$ reported no sickness presenteeism (45\% reported in the EWCS). It is interesting, however, that more than half (62.3\%) of the participants rated their health as good or very good, while on average reported experiencing three health problems in the last month. A relatively low proportion of the employees rated their health as poor or very poor (6.3\%); this is slightly less than estimates obtained in nationwide cross-sectional study by Farkas, Kragelj and Zaletel-Kragelj (2011; 9.6\%). Yet, these employees are at highest risk for sickness absenteeism or presenteeism and could benefit the most from interventions targeting their health.

Our results also indicated that higher frequency of perceived stress is associated with fewer implemented stress management interventions in the organisations. According to the research (Richardson and Rothstein, 2008), however, the effect of interventions most importantly depends on the intervention type. No conclusions regarding that can be made for our study, as no further details on the interventions were obtained. Still, similar to the findings of Richardson and Rothstein (2008) included organisations rarely reported implementation of organisational-level interventions such as changes to the way work is organised, changes to working time arrangements etc. (Table 3). The higher number of implemented activities for managing work-related stress could, however, reflect a higher awareness about employees' mental health and wellbeing, which could partially explain obtained association.

The main limitations of our study pertains the cross-sectional design and non-representative sample as the employees' participation was voluntary. Furthermore, despite the satisfactory validity of a single-item measure of stress re- 
ported by Elo and colleagues (2003), the measure was not additionally validated in our study. Also, the proposed regression model did not control for other working and psychosocial conditions.

\section{Conclusions}

Our study demonstrates that higher frequency of perceived stress in Slovenian chemical and other processing industry workers is associated with poorer self-rated health, higher number of health problems in the past month and higher frequency of sickness absenteeism and sickness presenteeism in the past year. The implemented activities for managing work-related stress in included organisations were relatively rare. Also, guidelines for their systematic implementation and research on their effectiveness are needed in the future.

\section{Acknowledgements}

Project 'Healthy on a square II' - workplace health promotion for employees in the chemical and other processing industries is a collaborative project of Chamber of Commerce and Industry of Slovenia - Association of Chemical Industries (lead partner), National Institute of Public Health (partner), Olympic Committee of Slovenia - Association of Sports Federations (partner), Sports Association Ljubljana (partner), Trade Union of the Chemical, Non-metal and Rubber Industry of Slovenia (partner), financially supported by The Health Insurance Institute of Slovenia.

\section{References}

ARONSSON, G., GUSTAFSSON, K. and DALLNER, M., 200o. Sick but yet at work. An empirical study of sickness presenteeism. Journal of Epidemiology and Community Health, vol. 54, no. 7, pp. 502-509.

BIRON, C., BRUN, J., IVERS, H. and COOPER, C.L., 2006. At work but ill: psychosocial work environment and well-being determinants of presenteeism propensity. JPMH, vol. 5, no. 4, pp. 26-37.

BORG, V., KRISTENSEN, T.S. and BURR, H., 20oo. Work environment and changes in self-rated health: a five year follow-up study. Stress Medicine, vol. 16, pp. 37-47.

BRUN, E. in MILCZAREK. M., 2007. Expert forecast on emerging psychosocial risks related to occupational safety and health. Luxembourg: European Agency for Safety and Health at Work (EU-OSHA).

COHEN, S., EVANS, G.W., STOKOLS, D. and KRANTZ, D.S., 1986. Behavior, Health, and Environmental Stress. New York: Plenum press.

COX, T., GRIFFITHS, A. and RIAL-GONZALEZ, E., 200o. Research on work related stress. Luxembourg: Office for Official Publications of the European Communities. 
ELO, A.L., LEPPÄNEN, A. and JAHKOLA, A., 2003. Validity of a single-item measure of stress symptoms. Scandinavian Journal of Work, Environment \& Health, vol. 29, no. 6, pp. 444-451.

ESCORPIZO, R., BOMBARDIER, C., BOONEN, A., HAZES, J.M.W., LACAILLE, D., STRAND, V. and BEATON, D, 2007 Worker productivity outcome measures in arthritis. Journal of Rheumatology, vol. 34, no. 6, pp. $1372-1380$.

EUROFOUND, 2012. Fifth European Working Conditions Survey. Luxembourg: Publications Office of the European Union.

EUROFOUND, 2017. Sixth European Working Conditions Survey 2015. Data visualisation. Available at: https://www.eurofound.europa.eu

FARKAS, J., PAHOR, M. and ZALETEL-KRAGELJ, L., 2011. Self-rated health in different social classes of Slovenian adult population: nationwide cross-sectional study. International Journal of Public Health, vol. 56, pp. 45-54.

GRAHAM, J.W., 2009. Missing data analysis: Making it work in the real world. Annual Review of Psychology, vol. 6o, pp. 549-576.

GONZÁLEZ, E. R., COCKBURN, W. and IRASTORZA, X., 2010. European Survey of Enterprises on New and Emerging Risks (ESENER) - Managing safety and health at work. Luxembourg: European Agency for Safety and Health at Work (EU-OSHA).

GUSTAFSSON, K. and MARKLUND, S., 2011. Consequences of sickness presence and sickness absence on health and work ability: a Swedish prospective cohort study. International Journal of Occupational Medicine and Environmental Health, vol. 24, no. 2, pp. 153-165.

IRASTORZA, X., MILCZAREK, M., COCKBURN, W. and EUROPEAN AGENCY FOR SAFETY AND HEALTH AT WORK (EU-OSHA), 2016. Second European Survey of Enterprises on new and emerging risks (ESENER-2) overview report: Managing safety and health at work. Spain: Publication office of the European Agency for Safety and Health at Work (EU-OSHA).

JOHNS, G., 2003. How methodological diversity has improved our understanding of absenteeism from work. Human Resource Management Review, vol. 13, no. 2, pp. 157-184.

JOHNS, G., 2009. Absenteeism or presenteeism? Attendance dynamics and employee well-being. In Cartwright, S. and Cooper, C. L., eds. The Oxford handbook of organizational well-being. Oxford: Oxford University Press, pp. 7-30.

JOHNS, G., 2010. Presenteeism in the workplace: A review and research agenda. Journal of Organizational Behavior, vol. 31, pp. 519-542. 
MACGREGOR, J.N., CUNNINGHAM, J.B. and CAVERLEY, N., 2008. Factors in absenteeism and presenteeism: life events and health events. Management Research News, vol. 31, no. 8, pp. 607-615.

MIRAGLIA, M. and JOHNS, G., 2016. Going to work ill: A meta-analysis of the correlates of presenteeism and a dual-path model. Journal of Occupational Health Psychology, vol. 21, nr. 3, pp. 261-283.

NOVAK T., SEDLAR N. and ŠPRAH L., 2013. Doživljanje stresa na delovnem mestu ter sopojavljanje zdravstvenih težav in izgorevanja pri različnih poklicnih skupinah. Zdravstveno varstvo, vol. 52: pp. 292-303.

PRÄTTÄLÄ, R., HELASOJA, V., LAAKSONEN, M., LAATIKAINEN, T., NICANDER, P. and PUSKA, P., 2001. Cindi health monitor, proposal for practical guidelines. Helsinki: National Public Health Institute.

RICHARDSON, K. M. and ROTHSTEIN, H. R., 2008. The Effects of Worksite Stress Management Intervention Programs: A Systematic Review. Journal of Occupational Health Psychology, vol. 13, pp. 69-93.

SCHNEIDERMAN, N., IRONSON, G., and SIEGEL, S. D., 2005. Stress and health: Psychological, behavioral, and biological determinants. Annual Review of Clinical Psychology, vol. 1, pp. 607-628.

STANSFELD, S. and CANDY, B., 2006. Psychosocial work environment and mental health - a meta-analytic review. Scandinavian Journal Of Work Environment \& Health, vol. 32, no. 6, pp. 443-462. 